\title{
Producing of Monolithic Layers of Silica for Thin-Layer Chromatography by Sol-Gel Synthesis
}

\author{
A.M. Frolova ${ }^{1}$, M.A. Chukhlieb ${ }^{1}$, A.V. Drobot ${ }^{1}$, A.P. Kryshtal $^{2}$, L.P. Loginova ${ }^{1}$ and \\ A.P. Boichenko ${ }^{*}, 1$ \\ ${ }^{I}$ Department of Chemical Metrology, Kharkov V.N. Karazin National University, Svoboda Square 4, 61077 Kharkov, \\ Ukraine \\ ${ }^{2}$ Department of Physics and Technology, Kharkov V.N. Karazin National University, Svoboda Square 4, 61077 Kharkov, \\ Ukraine
}

\begin{abstract}
In this work the approach for producing thin-layer chromatographic plates with monolithic layer of silica was proposed. The conditions of silica monolith synthesis were optimized by investigation of effects of different catalysts on the properties of obtained materials and addition of drying control chemical additive. The carrier for silica monolithic film was chosen and the method of surface modification was proposed. The properties of obtained monoliths were studied by FTIR and scanning electron microscopy (SEM). Produced thin-layer plates with monolithic layer of silica were successfully used for separation of test mixture of dyes.
\end{abstract}

\section{INTRODUCTION}

Creating of nanomaterials, e.g. nanopowders, nanotubes, nanocrystals, nanofilms etc., is one of the most important directions of material chemistry today [1,2]. Sol-gel techno$\operatorname{logy}$ is useful and flexible method for preparation of nanomaterial with different properties [3]. Sol-gel technology can be applied for obtaining of ceramic, glassy, films, powders, fibres and membranes, porous monolithic materials with ordered distribution of nanopores, hybrid organicinorganic materials, which contain inclusions of oxides, metals, organic fragments or special additives in form of pigments, luminophores etc., because of the opportunity to control properties of synthesized materials [1,2]. The useful properties of materials could be modified by controlling of the structure of materials on the molecular level that is important for providing of homogeneity and reproducibility of nanomaterial properties.

In analytical chemistry nanomaterials are used in separation sciences, sample preparation and test-methods of analysis [4-6]. Many scientific groups are working under the problems of creation and investigation of new materials, and fields of their application are discovered every year. That is why developments in this branch correspond for the most modern tendencies of material chemistry progress.

Application of monolithic materials in chromatography resulted in revolutionary improvements of well-known methods [6]. New monolithic stationary phases, which structure on micro- and nanolevels could be changed during sol-gel process led to development of fast analytical methods, allowing the separation of complex mixtures of analytes.

*Address correspondence to this author at the Department of Chemical Metrology, Kharkov V.N. Karazin National University, Svoboda Square 4, 61077 Kharkov, Ukraine; E-mail: boichenko@univer.kharkov.ua
Silica monolith is the solid continuous block of porous material with bimodal distribution dimensions of pores (macropores and mesopores). The creation of such material by sol-gel method on the beginning of 1990 initiated industrial production of monolithic columns on the basis of silica for high-performance liquid chromatography [7]. Due to very high permeability and efficiency, if monolithic columns are used, high speed of mobile phase without deterioration of separation quality could be achieved [8].

The first attempts to create and apply monolithic layers of silica for thin-layer chromatography separations were published 15 years ago [9]. However, only in 2002 were officially announced the origin of new mode of planar chromatography - ultra thin-layer chromatography (UTLC), in which the thin monolithic layers of silica were used for analyte separation $[10,11]$. On plates with thin monolithic layer of silica the test analysts are separated on a distance 1-3 cm that is much lower than in traditional thin-layer chromatography (TLC) $[10,11]$. Time of separation shortens up to 1-6 min and the volume of mobile phase decreases in 50-100 times $[10,11]$.

Now such plates are produced by Merck (Darmstadt, Germany), but this mode of chromatography did not get wide application, and its advantages were not fully investigated [12]. The reasons are (i) commercially produced plates are expensive; (ii) the conditions of ultra-thin layer chromatographic plates are unusual for traditional thin-layer chromatography. The commercial ultra-thin layer chromatographic plates now are used for analysis of small molecules with detection by using atmospheric pressure matrix-assisted laser desorption/ionization mass-spectrometry [13-16].

Recently original method for preparation of nanostructures thin layers of silica based on precipitation of pulverized substance by using special technique was offered [17]. Thinlayer chromatographic plates with monolithic porous polymer 
layer were developed for separation of large molecules: peptides and proteins [18].

The forming of films is a traditional area of sol-gel technology. However, producing monolithic layers for TLC presents specific difficulties: the creation of material with appropriate thickness and pore structure, prevention of monolith cracking, and fixing thin layers on a carrier [9]. Methods of producing bulk monolithic columns could not be applied to preparation of monolithic layers for thin layer chromatography. Moreover, many authors have tried to reproduce published methods of monolith column preparation without success [7].

The aim of this work is an optimization of conditions of sol-gel synthesis of monolithic layers of silica, its fixing on the carrier and application of obtained plates for separation of test mixture of analytes.

\section{BASIC STAGES OF SOL-GEL SYNTHESIS AND THEIR EFFECT ON THE PROPERTIES OF MONOLITHIC LAYERS OF SILICA}

Reactions of polycondensation of silicic acids are fundamental reactions in synthesis of nanostructural silica by sol-gel method. The kinetics of this reactions controls formation of interface between phases near transition of true solutions in sols that determine the properties of gels and structure of final material [3]. The most common precursors in the sol-gel process are tetraalkoxysilanes, e.g. tetraethoxysilane, $\mathrm{Si}\left(\mathrm{OC}_{2} \mathrm{H}_{5}\right)$, and tetramethoxysilane, $\mathrm{Si}\left(\mathrm{OCH}_{3}\right)$, which are abbreviated as TEOS and TMOS. Monolithic material preparation by sol-gel process consisted of the following stages:

Stage 1. Hydrolysis of precursors, which occurs by the nucleophilic attack of oxygen contained in water on the silicon [1]. The rate of hydrolysis decrease up to $\mathrm{pH} 7$ and increases from $\mathrm{pH} 7$ to highly basic conditions [1] with a minimum around $\mathrm{pH}$ 7. Hydrolysis is rapid and complete when catalysts are used, e.g. $\mathrm{H}^{+}$and $\mathrm{OH}^{-}$, ammonia, amines and another bases (N- methylimidazole or dimethylaminopyridine), $\mathrm{KF}$ and HF. Mechanism of hydrolysis includes the formation of hyhpervalents intermediates of silicon [1].

Stage 2. Forming of the sol. The sol must be deposited on the surface of the carrier.

Stage 3. Polymerization of monomers to form colloid particles and growth of particles. Speed of polycondensation depends to a great extent on the $\mathrm{pH}$ of the reaction solution and the catalysts used [3]. The minimum speed of polycondensation is observed at $\mathrm{pH}$ values around the isoelectric point of silica: $\mathrm{pH}$ 1-3. Colloidal particles cooperate by formation of covalent bonds that result in the creation of a three-dimensional net [19].

Stage 4. Ageing (ripening) of gel by compaction.

Stage 5. Drying of the gel. The solvents and other reagents are removed from the 3-dimensional structure of gel at this stage.

The main requirements for a monolithic layer of silica sorbent for thin-layer chromatography are following: sufficient thickness and porosity, homogeneity and mechanical stability, and the absence of cracks and exfoliation from the carrier. Analysis of the abovementioned stages leads to the following parameters which must be optimized for obtaining thin-layer plates with monolithic layer of silica: nature of solvent and precursor, type of hydrolysis (acid or alkaline), catalyst and other improving additives (stage 1,2); material and surface modification of the carrier (stage 3); duration of stages and effect of temperature (stage 3,4); temperature regime and speed of drying (stage 5).

\section{REAGENTS AND EQUIPMENT}

Tetraethoxysilane (TEOS) and tetramethoxysilane (TMOS) were used as precursors. Analytic grade acetic acid, urea, ammonia, hydrochloric acid; toluene; solution of hydrofluoric acid ( $25 \%$ by weight) from Ukrainian suppliers were used as catalysts. Polyethylene glycol (PEG) with average molar weight 1000 was from Fischamend, Austria. Cetylpyridinium chloride (CPC) (98.6\%); sodium dodecyl sulfate (SDS) (94.6\%); methanol (96.6 \%); ethanol (96.6 \%); $N, N-$ dimethylformaldehyde (DMFA), Tween-80 were from Merck, Germany. The dyes: bromocresol purple, bromocresol green, brilliant green, methyl yellow, phenolphthalein, methyl red, and neutral red were of analytical grade. The solution for glass etching $\left(\mathrm{NH}_{4} \mathrm{~F}\right.$ : $\mathrm{HF}$ 68:32 by volume) was used for surface treatment of the glass carriers. A Muffle furnace and a drying box were used for heat treatment of the monolith. The $10 \times 4 \mathrm{~cm}$ glass plates, aluminum foil and polyethylene terephthalate were tested as carriers of monolithic layers. The volume of reaction mixture on the surface of carrier was regulated by thresholds that were placed on the perimeter of the carrier. The structure of monolithic sorbents was investigated by using a scanning electron microscope JSM-840. Infra-red spectra were collected on a Thermo Nicolet Avatar 360 FTIR spectrometer.

\section{RESULTS AND DISCUSSION}

\section{Selection of Carrier for Monolithic Layer of Silica}

One of the important factors in preparation of plates for thin-layer chromatography is the considerable adhesion between carrier and reaction mixture. The three different carriers, which are often used in traditional thin-layer chromatography, were tested: aluminum foil, polyethylene terephthalate and glass. The reaction mixture, which often consists of TEOS or TMOS, solvent (short chain alcohol) and catalyst, creates individual drops and does not spread on the aluminum foil and polyethylene terephthalate. Insufficient spreading was observed also on the surface of glass, but the results were better than for other carriers.

The spreading of the mixture could be improved by reducing of surface tension by addition of surface active substances (surfactants). Three types of surfactants were tested: anionic - SDS, nonionic -Tween-80 and cationic CPC. Only additives of CPC improve the spreading of reaction mixture on the glass plate. In all the following syntheses the solution of $\mathrm{CPC}$ was added to reaction mixture to create concentration $7 \cdot 10^{-3} \mathrm{M}$.

The next stage was the surface modification of glass carrier. The glass plates were treated by $7 \mathrm{M}$ sodium hydroxide solution, which results in a more even distribution of reaction mixture on the surface of the glass. However, promising results were obtained after treatment of the glass plates with mixture for glass etching with high concentration of ammonium fluoride and hydrofluoric acid. Such surface 
modified glass has been used later as carriers for monolithic thin layer of silica.

\section{OPTIMIZATION OF THE CONDITIONS OF SILICA MONOLITH SYNTHESIS}

The methods of monolithic layers of silica synthesis by acid and base hydrolysis of precursors described in literature $[9,20]$, were tested and modified. The basic aspects of methods, changes that were made and results are presented below.

Method 1: $1 \mathrm{ml}$ of TMOS, $0.5 \mathrm{ml}$ of $0.01 \mathrm{M}$ acetic acid, $54 \mathrm{mg}$ polyethyleneglycol, $30 \mathrm{mg}$ urea, CPC and $0.2 \mathrm{ml}$ of methanol were mixed and then stirred during 40 minutes. The reaction mixture was distributed on the surface modified carrier and dried at room temperature during 24 hours. Then the plates were dried 2 hours at $300{ }^{\circ} \mathrm{C}$. The obtained layer of monolithic sorbent was not transparent; it also cracked and exfoliated from the carrier.

Method 2: $0.5 \mathrm{ml}$ methyltrimethoxysilane MTMOS, 1.5 $\mathrm{ml}$ of methanol, $0.18 \mathrm{~g}$ of bromocresol purple (BCP) in acidic form were mixed according to Ref. [9]. We have tried to modify this method by replacing methyltrimethoxysilane with tetramethoxysilane. The CPC was also added to this reaction mixture. An $11 \mathrm{M}$ solution of $\mathrm{HCl}$ was added to the reaction mixture. The mixture was energetically stirred for 4 minutes and then $0.2 \mathrm{ml}$ of the mixture was distributed on the glass carrier. Then the plate was dried for 24 hours at room temperature and finally washed with ethanol. Unfortunately the BCP could not be completely washed from the layer of sorbent and the obtained monolithic layer is not appropriate for practical use. The obtained sorbent was also red due to presence of $\mathrm{BCP}$, monolithic layer of sorbent cracked and exfoliated from carrier.

Method 3: The bromocresol purple was replaced with colourless in acidic environment dye - phenolphthalein. The reaction mixture consisted of $0.6 \mathrm{ml}$ of TEOS, $1.5 \mathrm{ml}$ of methanol, $0.18 \mathrm{~g}$ of phenolphthalein, CPC and 3 drops of 11 $\mathrm{M} \mathrm{HCl}$ was stirred during only 4 minutes due to fast polymerization and transferred on the carrier, dried 24 hours at room temperature. Then temperature was increased to 300 ${ }^{\circ} \mathrm{C}$ and carrier with reaction mixture was aged at this temperature 120 minutes. Obtained layer of sorbent was turbid, but cracked and exfoliated from carrier.

Method 4: The drying control chemical additives (DCCA) were proposed in 1984 to avoid crack formation during the drying of gels $[1,21]$. The one of the useful DCCA, which was proposed in [22], is dimethylformaldehyde. Dimethylformaldehyde was added to reaction mixture for prevention of monolith cracking. The DCCA displaced the water from the surface of the $\mathrm{SiO}_{2}$ gel matrix [23] and reduced the differential drying stresses by minimizing the differential rates of evaporation and ensuring a gel structure with uniform pore and particle sizes [24]. Reaction mixture consisted from $0.8 \mathrm{ml}$ of TEOS, $0.3 \mathrm{ml}$ of solution with mass fraction $\mathrm{HF} 25 \%, \mathrm{CPC}$, and $0.4 \mathrm{ml}$ of DMFA was stirred during 4 minutes, distributed on the carrier and dried for $40{ }^{\circ} \mathrm{C}$ during 120 minutes. Then temperature gradually was increased to $80{ }^{\circ} \mathrm{C}$ and carrier with reaction mixture was aged at this temperature during 120 minutes. The white sorbent was hard, fastened on carrier and without cracks.

Method 5: In the previous method the HF, which could be catalyst of sol-gel process due to presence of $\mathrm{H}^{+}$and $\mathrm{F}^{-}$ ions, was replaced with $0.2 \mathrm{ml}$ of $1 \mathrm{M} \mathrm{HCl}$. Obtained layer of sorbent was hard, fastened on carrier and without cracks. Sorbent was transparent.

Method 6: The method 4 was modified by changing CPC for a natural surfactant - gelatine. Reaction mixture consisted of $0.8 \mathrm{ml}$ of TEOS, $0.4 \mathrm{ml}$ of ethanol, $0.2 \mathrm{ml}$ of 1 $\mathrm{M} \mathrm{HF}$, and $0.12 \mathrm{ml}$ of $3 \%(\mathrm{w} / \mathrm{w})$ solution of gelatine was stirred 5 minutes, distributed on the carrier and dried for 24 hours at room temperature. Then the temperature increased to $300{ }^{\circ} \mathrm{C}$ and the carrier with the reaction mixture was aged 2 hours at this temperature. The obtained layer of sorbent was transparent, cracked and exfoliated from carrier.

Method 7: The reaction mixture consisted of $0.8 \mathrm{ml}$ TEOS, CPC, and $0.4 \mathrm{ml}$ of $3 \mathrm{M} \mathrm{NH}_{3}$; ethanol was stirred during 4 minutes, distributed on the carrier and dried 2 hours at $40{ }^{\circ} \mathrm{C}$. Then the temperature was gradually increased to 80 ${ }^{\circ} \mathrm{C}$ and the carrier with the reaction mixture was aged 2 hours at this temperature. The white sorbent was hard and adhered to the carrier without cracks.

Thus, acid hydrolysis of TEOS in the presence of DMFA and $\mathrm{CPC}$ (method 4) results in homogeneous monolithic layers of silica without cracks, with good adhesion to the carrier. DMFA, in contrast to other solvents and organic compounds, which are used as additives for control of drying, successfully combines low surface tension and high boiling temperature. To reduce the speed of solvent evaporation at the stage of monolith drying, the carrier with the reaction mixture was covered by glass plate, which was removed after drying.

\section{MONOLITHIC LAYERS STRUCTURE}

The effect of the sol-gel process conditions on the structure of materials, which was promising for application of thin-layer chromatography, were studied by scanning electronic microscopy and Fourier-transformed infra-red spectroscopy (FTIR). The monolithic blocks of silica for these investigations were obtained by forming in the tube of $1 \mathrm{ml}$ medical syringes. After drying, the monoliths were aged at different temperatures.

The structure of the product that was obtained by method 4 (Fig. 1) is similar to structure of silica monolith sample that was described in literature [9]. Porosity of material decreases from the centre of sample to its surface that was also observed by other authors [9]. The aging of monolith at a temperature $650{ }^{\circ} \mathrm{C}$ leads to decreasing of pore size (Fig. 2). This process enhanced at higher temperatures (Fig. 3). It is known that at $1050{ }^{\circ} \mathrm{C}$ the caking of silica is observed [1]. Method 7 of alkaline hydrolysis leads to obtaining of material with macropores (compare Fig. 2 and Fig. 4).

The monolithic samples studied by SEM were also studied by FTIR-spectroscopy. Samples of monoliths were triturated in agate mortar with $\mathrm{KBr}$ and then tablets were formed. In Figs. (5-8) the spectra of monoliths synthesized by method 4 and dried at $80^{\circ} \mathrm{C}$ (Fig. 5) or $650{ }^{\circ} \mathrm{C}$ (Fig. 6), 


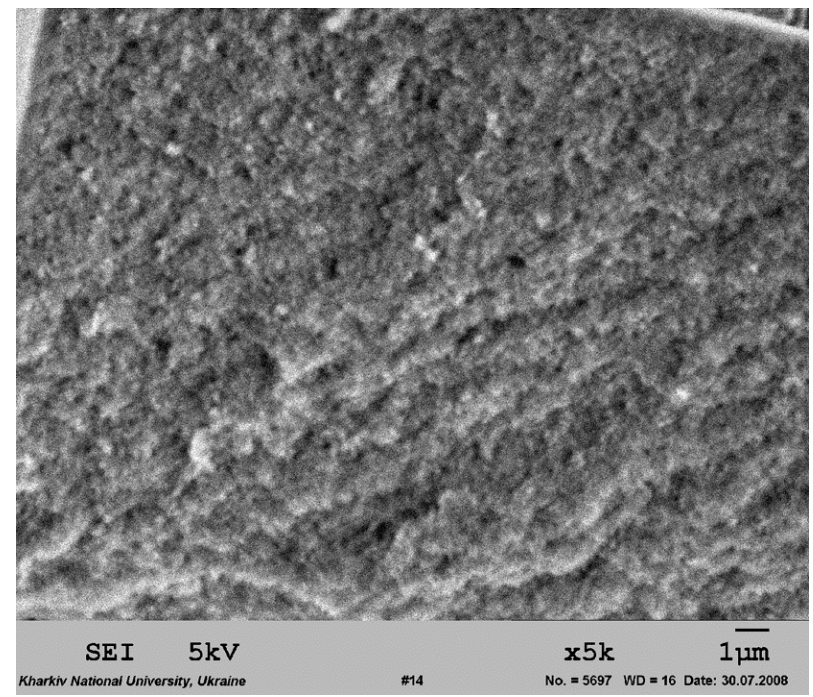

Fig. (1). Structure of silica monolith synthesized by method 4 and dried at $80^{\circ} \mathrm{C}$.

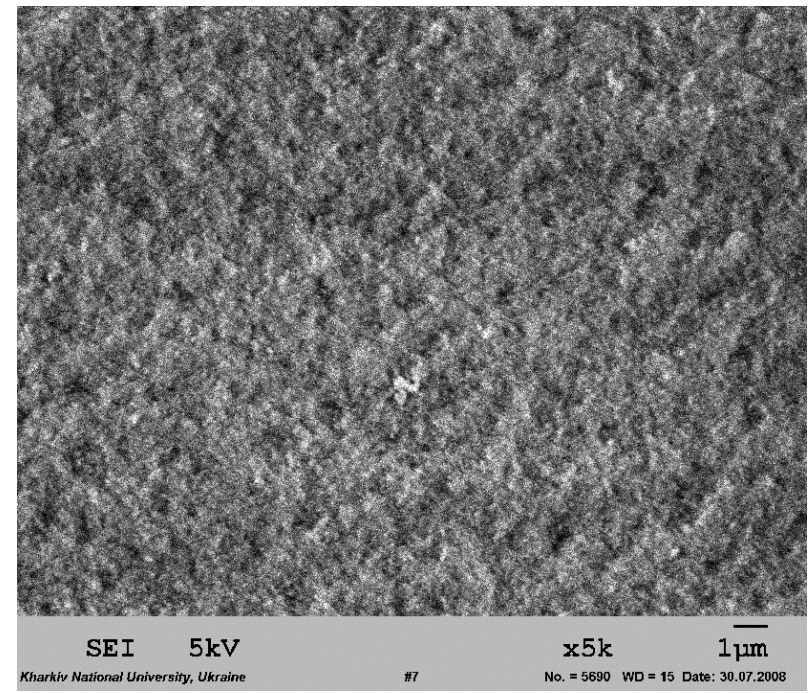

Fig. (2). Structure of silica monolith synthesized by method 4 and dried at $650{ }^{\circ} \mathrm{C}$

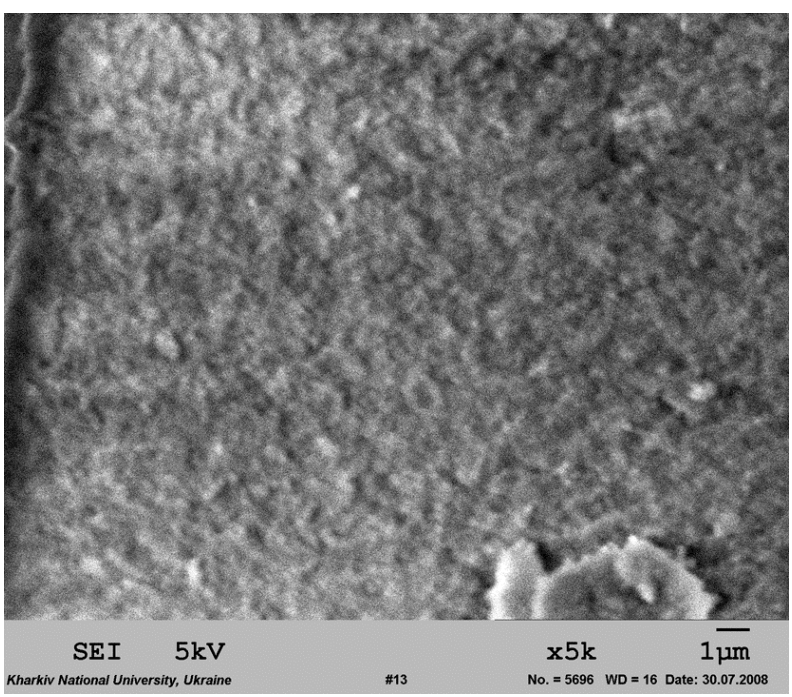

Fig. (3). Structure of silica monolith synthesized by method 4 and dried at $900^{\circ} \mathrm{C}$.

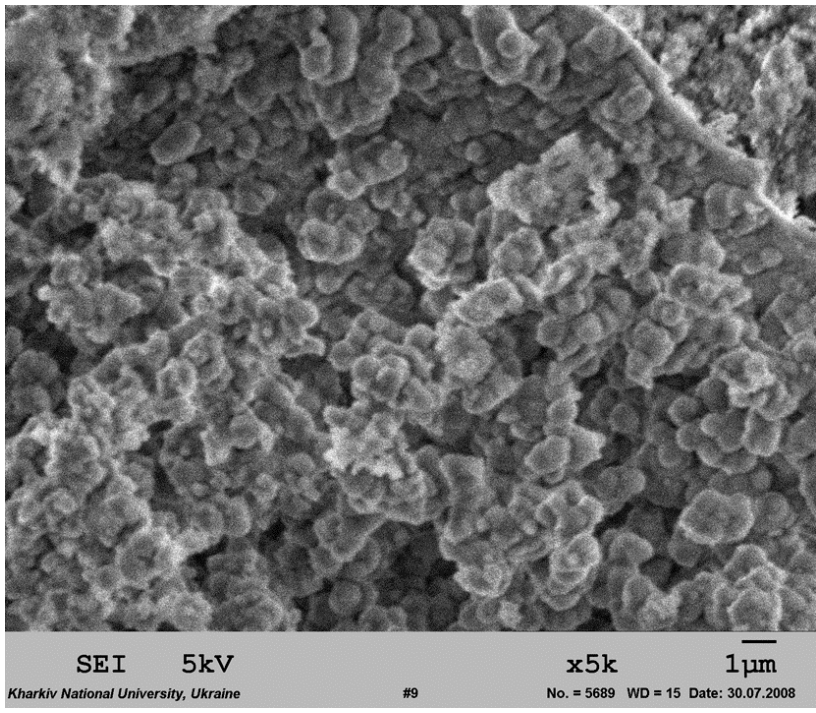

Fig. (4). Structure of silica monolith synthesized by method 7 and dried at $650^{\circ} \mathrm{C}$.

and synthesized by method 7 and dried at $80{ }^{\circ} \mathrm{C}$ (Fig. 7) or $650{ }^{\circ} \mathrm{C}$ (Fig. 8) are presented. The wide band of absorption at $3400 \mathrm{~cm}^{-1}$, where different isolated and protonated groups $\mathrm{SiO}-\mathrm{H}$ absorbs as well as hydrogen bonds of water, is observed on spectra of all samples. The silanol groups absorb at $960 \mathrm{~cm}^{-1}$ and $1600 \mathrm{~cm}^{-1}$ [25] (Figs. 5, 7). A decreasing of number of silanol groups is observed if the temperature increases (Figs. 6, 8). The aging of silica monolith at $650{ }^{\circ} \mathrm{C}$ results in collapse of silanol groups on the surface of monolith, which is important for their application in thin-layer chromatography (Figs. 6, 8). It is interesting that qualitatively it could be concluded that number of silanol groups on the surface of monolith synthesised by alkali hydrolysis (method 7) is higher than on the surface of monolith synthesised by acidic hydrolysis (Figs. 5, 7).

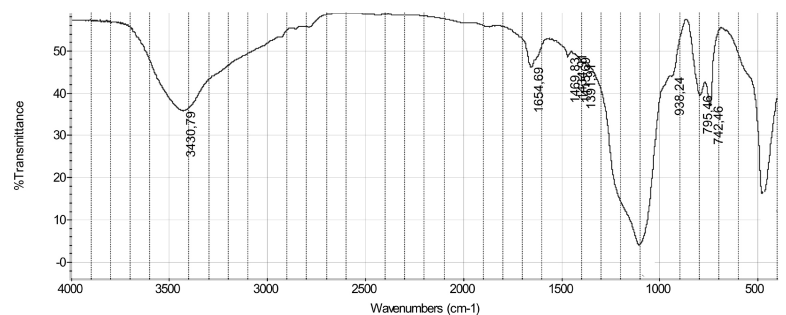

Fig. (5). FTIR-spectrum of silica monolith synthesized by method 4 and dried at $80^{\circ} \mathrm{C}$.

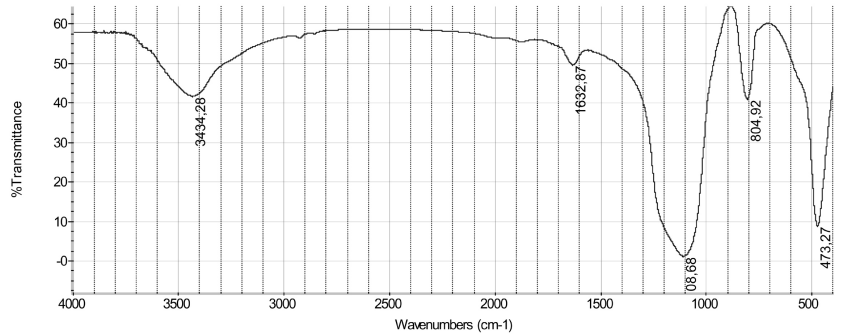

Fig. (6). FTIR-spectrum of silica monolith synthesized by method 4 and dried at $650{ }^{\circ} \mathrm{C}$. 


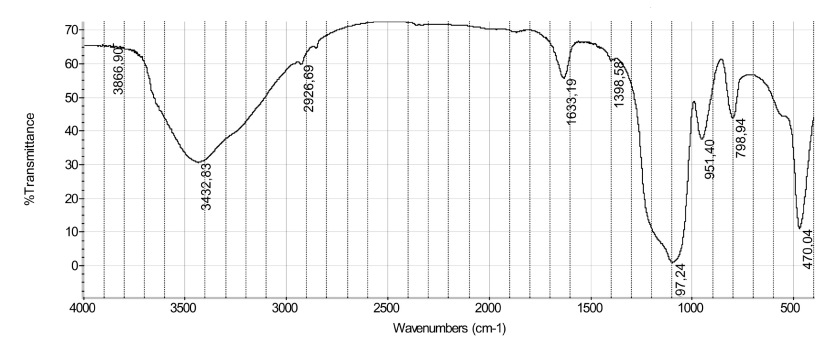

Fig. (7). FTIR-spectrum of silica monolith synthesized by method 7 and dried at $80^{\circ} \mathrm{C}$.

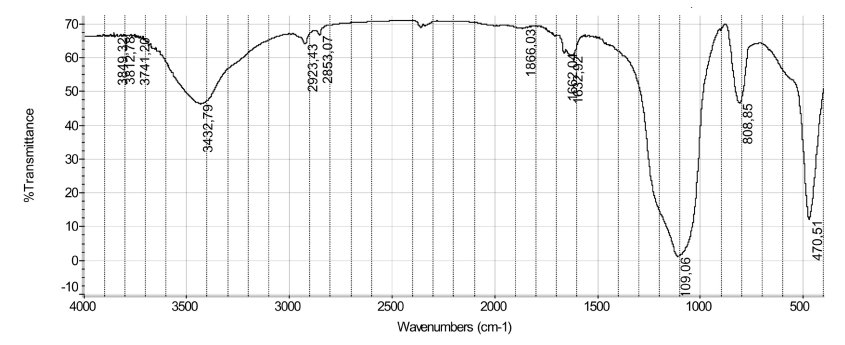

Fig. (8). FTIR-spectrum of silica monolith synthesized by method 7 and dried at $650{ }^{\circ} \mathrm{C}$.

\section{APPLICATION OF OBTAINED THIN-LAYER CHRO- MATOGRAPHIC PLATES WITH MONOLITHIC SILICA FOR SEPARATION OF TEST MIXTURE OF DYES}

Thin-layer chromatographic plates with monolithic film of silica synthesised by method 4 and 7 were used for separation of test mixture of dyes. The mobile phase consisted of methanol and toluene (20:80 v/v) was used for separations. The usual chambers for thin-layer chromatography with previous saturation by components of mobile phase were used. The chromatograms were digitized by using digital camera Canon 570. Then, chromatograms were treated by Adobe Photoshop 7.0 program for construction of densitograms. Fig. (9) presents chromatograms and densitograms that were obtained for separation of dyes brilliant green and neutral red on silica monolith synthesized by method 7 . The full separation of dyes was observed on distance $1 \mathrm{~cm}$. The time of separation was 5 minutes. However, spots of dyes have had irregular form and efficiency of separation was low (Fig. 9). This could be explained by more wide pores distribution for monolith synthesized by method 7 and their inhomogeneity. Better results of dyes separation were obtained on monolithic sorbent that was synthesised by acid hydrolysis (method 4). Chromatogram of separation of bromocresol green, methyl red and methyl yellow is presented in Fig. (10). Test mixture of dyes were fully separated in a distance of $1.5 \mathrm{~cm}$ in 7 minutes. Spots of dyes have a regular form and the forms of peaks on densitogram are symmetrical.

During the investigation of properties of obtained chromatographic plates with monolithic sorbent an important practical property was discovered. Chromatographic spots could be washed from the plates by mobile phase and after drying at room temperature, so that the thin-layer chromatographic plates could be used again for separation. Results of dyes separation had a good reproducibility even after 3-4 cycles of chromatographic plates regeneration.

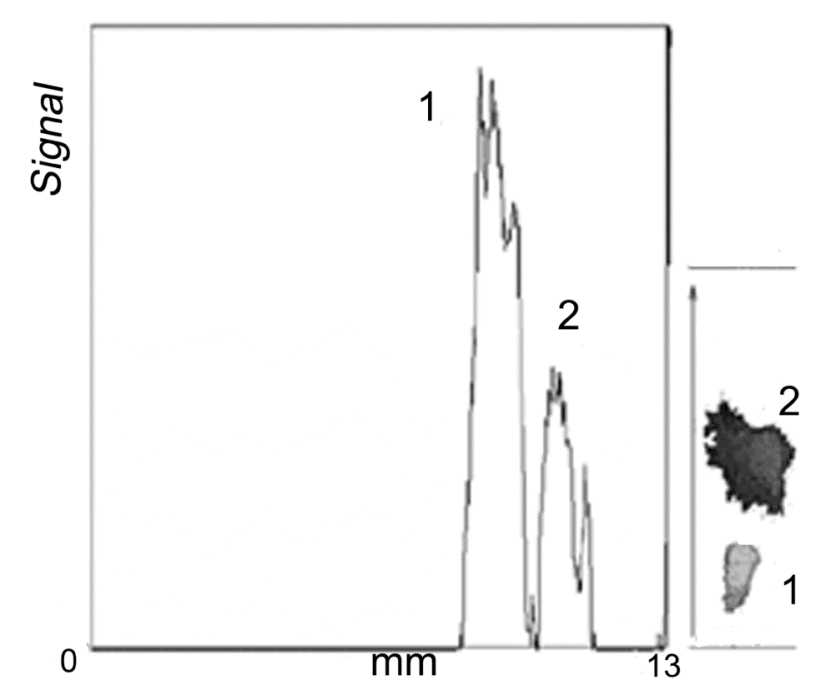

Fig. (9). Chromatogram and videodensitogram of brilliant green (1) and neutral red (2) on thin-layer chromatographic plate with monolithic sorbent synthesized by method 7 .

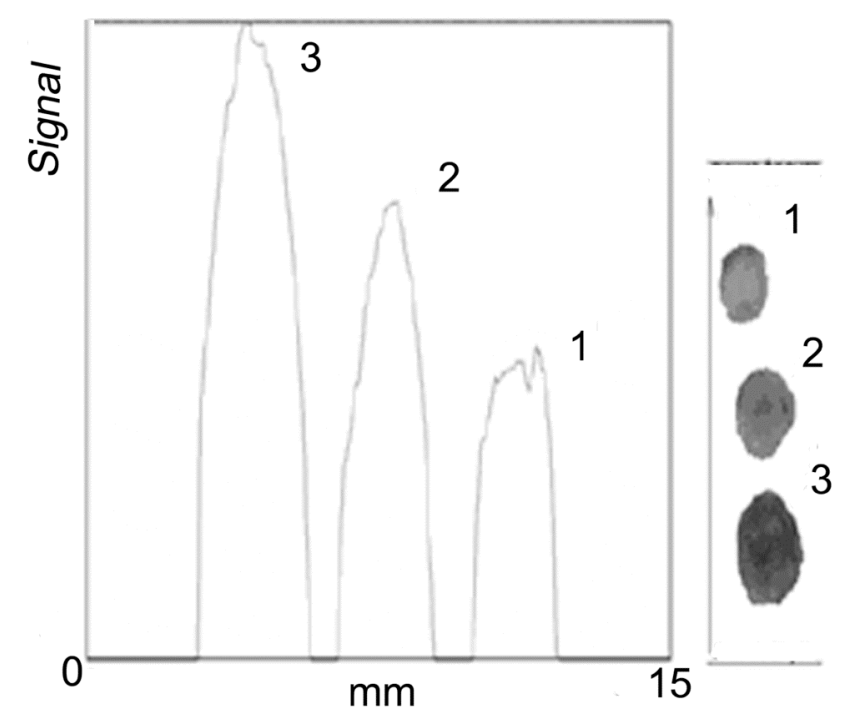

Fig. (10). Chromatogram and videodensitogram of bromocresol green (3), methyl red (2) and methyl yellow (1) thin-layer chromatographic plate with monolithic sorbent synthesized by method 4.

\section{CONCLUSIONS}

In this work the method of obtaining of thin-layer chromatographic plates with monolithic silica sorbent was proposed. The method consisted of the sol-gel synthesis of monolithic layers of silica by acid hydrolysis of TEOS with HF as catalyst and additives of dimethylformaldehyde, cetylpyridinium chloride and ethanol as solvent, distributing of reaction mixture on glass carrier and drying of monolith. The surface of glass carrier was initially activated by a solution of $\mathrm{HF}$ and $\mathrm{NH}_{4} \mathrm{~F}$.

Obtained plates with monolithic layer of silica were successfully tested on separation of test dyes. Obtained plates with monolithic layer of silica have next advantages in comparison to traditional plates for TLC: (i) high speed of separation; (ii) short distance, which is necessary for full 
separation of analytes; (iii) opportunity for plate regeneration; (iv) considerable reduction of toxic organic solvent utilization.

\section{REFERENCES}

[1] Brinker C, Scherer G. Sol-gel science. The physics and chemistry of sol-gel processing. Boston: Academic Press 1990.

[2] Sakka S, Kozuka H. Sol-gel science and technology. Processing characterization and application. sol-gel processing. Kluwer Boston, Dordrecht, London: Academic Publishers 2005; vol. 1: pp. 147.

[3] Shabanova NA, Sarkisov PD. Principles of sol-gel technology for nanodisperse silica in Russian. Moscow: IKTs Akademkniga 2004.

[4] Svec F. Less common applications of monoliths: preconcentration and solid-phase extraction. J Chromatogr B 2006; 841: 52-62.

[5] Siouffi A-M. Silica gel-based monoliths prepared by the sol-gel method: facts and figures. J Chromatogr A 2003; 1000: 801-18.

[6] Unger KK, Skudas R, Schulte MM. Particle packed columns and monolithic columns in high-performance liquid chromatography comparison and critical appraisal. J Chromatogr A 2008; 1184: 393-415.

[7] Guiochon G. Monolithic columns in high-performance liquid chromatography. J Chromatogr 2007; 168: 101-68.

[8] Puy G, Demesmay C. Electrochromatographic behavior of silica monolithic capillaries of different skeleton sizes synthesized with a simplified and shortened sol-gel procedure. Electrophoresis 2006; 27 (20): 3971-80.

[9] Tsionsky M, Vanger A, Lev O. Macroporous thin films for planar chromatography. J Sol-Gel Sci Techn 1994; 2 (1-3): 595-9.

[10] Hauck H, Schulz M. Ultra thin-layer chromatography. J Chromatogr Sci 2002; 40(10): 550-2.

[11] Hauck H, Schulz M. Ultra thin-layer chromatography. Chromatographia Suppl 2003; 57(1): 313-5.

[12] Halkina T, Sherma J. Comparative evalution of the performance of silica gel TLC plates and irregular and spherical-particle HPTLC plates. Acta Chromatogr 2006; 17: 261-71.

[13] Salo P, Salomies H, Harju K, et al. Analysis of small molecules by ultra thin-layer chromatography-atmospheric pressure matrix- assisted laser desorption/ionization mass-spectrometry. J Am Soc Mass Spectrom 2005; 16: 906-15.

[14] Salo P, Vilmunen S, Salomies H, Ketola R, Kostiainen R. Twodimensional ultra-thin-layer chromatography and atmospheric pressure matrix-assisted laser desorption/ionization mass spectrometry in bioanalysis. Anal Chem 2007; 79(5): 2101-8.

[15] Kauppila T, Talaty N, Salo P, et al. New surfaces for desorption electrospray ionization mass spectrometry: porous silicon and ultrathin layer chromatography plates. Rapid Commun Mass Spectrom 2006; 20: 2143-50.

[16] Talian I, Orinak A, Preisler J, et al. Comparative TOF-SIMS and MALDI TOF-MS analysis on different chromatographic planar substrates. J Sep Sci 2007; 30: 2570-82.

[17] Bezuidenhout L, Brett M. Ultrathin layer chromatography on nanostructured thin films. J Chromatogr A 2008; 1183: 179-85.

[18] Bakry R, Bonn G, Mair D, Svec F. Monolithic porous polymer layer for the separation of peptides and proteins using thin-layer chromatography coupled with MALDI-TOF-MS. Anal Chem 2007; 79: 486-93.

[19] Douglas A, Kenneth J. Bridged polysilsesquioxanes. Highly porous hybrid organicinorganic materials. Chem Rev 1995; 95 (5): 143142 .

[20] Wang P, Chen Z, Chang H. An integrated micropump and electrospray emitter systembased on porous silica monoliths. Electrophoresis 2006; 27 (20): 3964-70.

[21] Sakka S, Almeida R. Handbook of sol-gel science and technology: processing, characterization and applications: characterization and properties of sol-gel materials and products. Boston, Dordrecht, London: Kluwer Academic Publishers 2005; vol. 1.

[22] Adachi T, Sakka S. The role of N,N-dimethylformamide, a DCCA, in the formation of silica gel monoliths by sol-gel method. J Non-Crystalline Solids 1988; 99: 118-28.

[23] Khimich NN. On the problem of drying of monolithic silica gel. Glass Phys Chem 2004; 30(1): 107-8.

[24] Haranath D, Venkateswara RA, Wagh PB. Influence of DCCAs on optical transmittance and porosity properties of TMOS silica aerogels. J Porous Mater 1999; 6: 55-62.

[25] Nadargi DY, Latthe SS, Rao AV. Effect of post-treatment (gel aging) on the properties of methyltrimethoxysilane based silica aerogels prepared by two-step sol-gel process. J Sol-Gel Sci Technol 2009; 49: 53-9.

(C) Frolova et al.; Licensee Bentham Open.

This is an open access article licensed under the terms of the Creative Commons Attribution Non-Commercial License (http://creativecommons.org/licenses/by-nc/ 3.0/) which permits unrestricted, non-commercial use, distribution and reproduction in any medium, provided the work is properly cited. 